\title{
Visual Feedback and Human Performance in the Foot Mouse Control
}

\author{
Seung-Kweon Hong ${ }^{1}$, Seon-Soo Kim ${ }^{2}$ \\ ${ }^{1}$ Department of Industrial \& Management Engineering, Korea National University of Transportation, \\ Chungju-si, 380-702 \\ ${ }^{2}$ Korea Atomic Energy Research Institute, Daejeon, 305-353
}

\begin{abstract}
Objective: The aim of this study is to investigate visual feedback effects and human performance in the foot mouse control. Background: Generally, computer mouse tasks are controlled by visual feedback. In order to understand the characteristics of a foot mouse control, it is important to investigate the patterns of visual feedback involved in foot-mouse control tasks. Human performance of foot mouse control is also an important factor to understand the foot mouse control. Method: Three types of mouse control were determined to investigate visual feedback effects and human performance in the foot mouse control. Visual feedback effects in the foot mouse control were compared with those of a typical hand mouse. The cursor movement speed and mental workload were measured in the three types of tasks and two types of mouses. Results: Mouse control tasks with an element of homing-in to the target were more quickly performed by the hand mouse than the foot mouse. Mental workload was also higher in the foot mouse than the hand mouse. However, in the steering movement, human performance of the foot mouse control was not lower than that of the hand mouse control. Visual feedback in the foot mouse control was less required than in the hand mouse control. Conclusion: The foot mouse was not efficient in the most mouse control tasks, compared to the hand mouse. However, the foot mouse was efficient in the steering movement, moving a cursor within a path with lateral constraints. Application: The results of this study might help to develop the foot mouse.
\end{abstract}

Keywords: Foot mouse control, Fitts' law, Steering law, Visual feedback, Mental workload

\section{Introduction}

현재 컴퓨터에서 사용되는 입력장치는 마우스, 키보드부터 스캐너, 태블릿, OCR, 디지타이져, 트랙볼, 라이트펜 등 다 양하다. 그 중에서도 GUI(Graphical User Interface) 체계 에서 가장 보편적으로 이용되는 입력장치는 마우스라고 할 수 있다. 마우스에 대한 인간공학적 연구는 신체에 부담을 경감시키고 휴대성을 높이며, 조작의 편의성 및 포인팅의
정확성을 높이는 방향 등 다양한 측면에서 수행되어 왔다. 그러나 일반적인 마우스를 사용할 수 없는 지체 장애인들 을 위한 대체 마우스의 연구에는 활발히 수행되고 있지 못한 형편이다. 보다 사용성이 좋은 대체 마우스가 개발된다면 지 체 장애인뿐만 아니라 일반인에게도 사용할 수 있는 입력장 치가 될 것이다.

이에 본 연구에서는 대체 마우스 중에서도 발을 이용하여 마우스를 제어하는 발 마우스를 연구의 대상으로 선정하였다. 발 마우스에 대한 연구는 국내외에서 여러 차례 수행되어

Corresponding Author: Seung-Kweon Hong. Department of Industrial \& Management Engineering, Korea National University of Transportation, Chungju-si, 380-702.

Mobile: +82-10-9797-5389, E-mail: skhong@ut.ac.kr

Copyright@2012 by Ergonomics Society of Korea(pISSN:1229-1684 eISSN:2093-8462). All right reserved.

(c) This is an open-access article distributed under the terms of the Creative Commons Attribution Non-Commercial License(http://creativecommons.org/licenses/by-nc/3.0/), which permits unrestricted non-commercial use, distribution, and reproduction in any medium, provided the original work is properly cited. http://www.esk.or.kr 
왔다. Lee et al. (2004)는 목표물 선택작업에서 발 마우스 의 최적 반응-조종 이득값에 대한 연구를 수행하였고, 작업 난이도가 3.0 이하에서 반응-조종 이득값은 0.256 이 가장 적절하다는 실험결과를 제시하였다. Hong and Park(2008) 은 발 마우스를 사용할 때, 시각적 피드백을 요구하지 않는 탄도운동의 범위를 조사하였다. 그리고 Kang et al. (2008) 은 상용화되어 있는 발 마우스보다 사용성이 향상된 발 마 우스의 개발하였다. Springer and Siebes (1996)는 발 마우 스를 사용할 때와 손 마우스를 사용할 때의 수행도를 평가 하였다. 발 마우스 사용에 대한 훈련없이 실험이 수행되었다 는 한계성은 있지만, 손 마우스 사용할 때와 비교하여 발 마 우스는 $43 \%$ 의 수행속도 저하를 보였고, 에러율은 $56 \%$ 의 높았다. Garcia and $\mathrm{Vu}(2011)$ 은 발 마우스 사용에 대한 훈 련을 받기 전과 받은 후의 발 마우스 수행도의 차이를 조사 하였다. 트랙볼과 발 마우스에 대한 훈련 전후의 비교분석에 서, 트랙볼은 유의한 훈련효과를 보지 못했지만, 발 마우스 는 훈련효과를 볼 수 있었다.

본 연구에서는 발 마우스를 사용할 때의 인간 수행도를 평 가하고, 발 마우스 작업을 수행하는 과정에 시각적 피드백의 효과를 분석하고자 한다. 통제집단을, 손 마우스를 사용하는 경우의 수행도와 시각적 피드백의 효과로 설정하고 발 마우 스와 비교 · 분석하고자 한다.

본 연구에서 피실험자들은 세 가지 마우스 컨트롤 작업으 로 설정하였다. 마우스를 이용하여 커서를 이동시키는 작업 에 대한 기존연구들은 주로 Fitts 운동(목표물 선택작업)의 대상작업으로 설정하였다(Mackenzie et al., 1999). 그러나 Fitts 운동은 원하는 목표물에 커서를 위치시키는 과정에서 만 시각적 피드백을 필요로 하는 작업이다. 따라서 본 연구 에서는 커서를 이동시키는 과정에서 시각적 피드백을 요구 하는 Steering 운동을 추가하였다. 또한 Steering 운동과 Fitts 운동의 혼합형 작업도 연구 대상 작업으로 설정하였다.

\section{Mouse Control Tasks and Visual Feedback}

본 연구의 첫 번째 연구대상 작업은 Fitts 운동이다. Fitts 운동에서 커서이동의 정확성과 속도 사이의 관계를 묘사한 모델이 Fitts' law다. 이 모델은 1954년 Fitts에 의해 제안되 었으며, 특정표적을 향해 이동하는 손의 이동시간이 작업의 난이도(Index of Difficulty) 와 비례관계를 갖는다는 법칙이 다(Fitts, 1954).

$$
M T=a+b \log _{2}(2 A / W)
$$

여기서 MT(Movement Time)는 동작을 완수하는 데 필 요한 평균시간, $\mathrm{a}$ 와 $\mathrm{b}$ 는 상수로써 작업의 특성이나 작업 숙 련도에 따라 결정된다. A (Amplitude)는 대상 물체의 중심 으로부터 측정한 거리이며, $\mathrm{W}$ 는 움직이는 방향을 축으로 하 였을 때 측정되는 목표물의 폭이다.

Fitts' 이동작업에 소요되는 시간은 이동하는 거리와 표적 의 너비에 의해 결정된다. 표적에 커서를 위치시키는 과정에 서 커서의 이동속도는 감속이 된다. 이러한 속도의 감소는 커서가 표적의 너비 안에 들어갈 수 있도록 조정하면서 커서 를 움직이기 때문에 발생하는 현상이다. 즉, 이 과정에서 시 각적 피드백이 연속적으로 이루어진다. 따라서 이 과정을 시 각적 조절이동(Visually-controlled movement) 단계라고 한다. 반면에 커서가 출발하는 단계에서는 표적의 너비와는 상관없이 표적을 향해 가속도를 낼 수 있고, 이 단계에서 커 서는 탄도운동을 하게 된다. 이러한 탄도운동과 시각적 조 절이동에 의해 Figure 1 과 같은 속도의 변화가 나타날 수 있다.

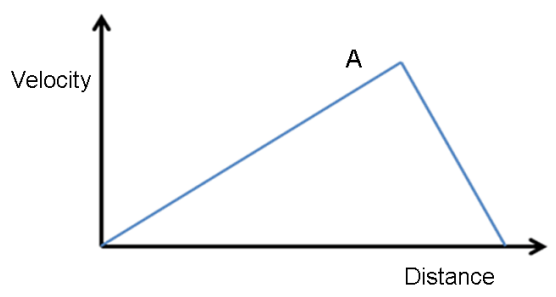

Figure 1. Movement distance and velocity in the Fitts' movement

두 번째 대상작업은 Steering 이동작업이다. 이 작업에서 소요되는 시간을 묘사한 모델은 Steering Law라고 칭하였 다(Acott and Zhai 1997). 이 법칙은 식 (2)와 같이 표현될 수 있다. 다양한 궤도(예, 직선 또는 원)에 대한 Steering 법칙이 성립될 수 있다.

$$
M T=a+b \int_{c} \frac{d s}{W(s)}
$$

여기서 c는 Steering하는 궤도를 나타낸다. $a$ 와 b는 상 수로써 작업의 특성이나 작업 숙련도에 따라 결정된다. 이 동 궤도가 직선일 경우에는 식(3)과 같이 표현될 수 있다 (Drury, 1971). 이 식은 궤도의 폭과 궤도상을 움직이는 속 도 사이에 비례관계가 있음을 보이고 있다.

$$
M T=a+b(A / W)
$$

여기서 $\mathrm{MT}$ 는 동작을 완수하는 데 필요한 평균시간, $\mathrm{a}$ 와 
$\mathrm{b}$ 는 상수로써 작업의 특성이나 작업 숙련도에 따라 결정된 다. $\mathrm{A}$ 는 대상 물체의 중심으로부터 측정한 거리이며, $\mathrm{W}$ 는 이동경로의 폭이다. 이 법칙은 궤도상을 움직이는 물체의 속 도가 궤도의 폭에 반비례한다는 일반적인 원리에서 유추된 법칙이다. 따라서 움직이는 물체의 속도가 일정한 속도를 유지하는 경우에 통용되고 있다(Winsum 1996; Godthelp 1988).

따라서 커서가 궤도상을 움직이는 동안 커서의 속도를 측 정하면 Figure 2와 같이 커서의 속도는 일정하게 유지될 것 이다. 속도는 궤도의 폭에 반비례 할 것이다. 이는 커서를 이 동시키면서 궤도 내에 커서를 유지하기 위하여 계속 시각적 조절이동을 하고 있음을 뜻한다.

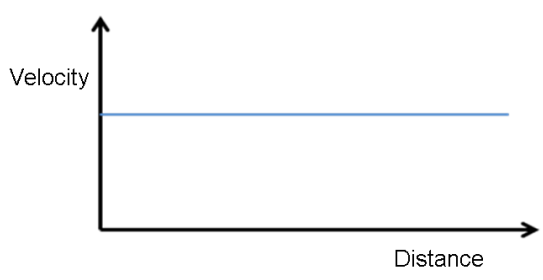

Figure 2. Movement distance and velocity in the steering movement

계층적으로 구성된 메뉴에서 특정한 메뉴를 선택하기 위 해 커서를 이동시키는 커서이동은 Fitts' Law와 Steering Law가 복합된 형태다. 궤도 내에서 일정한 속도로 이동할 수 없기 때문에 Steering law라고 할 수 없다. 시작점에서는 정의 가속도가 생기고, 목표물에 접근하면서 부의 가속도가 생긴다. 한편 어느 지점에서 출발하여 이동을 시작하고 목표 물에 도착하여 멈추기 때문에 Fitts' Law의 성격을 갖지만, 이동궤도의 제약으로 인해, 원래의 Fitts' Law와는 다르다.

이러한 성격을 갖는 커서이동 시간을 모델링 하려는 연구 들이 수행되었다(Dennerlein et al., 2000; Hong and Kim, 2005). 이러한 이동작업시간에 관한 모델 중에서 가장 설명 력이 좋은 모델은 식(4)다.

$$
M T=a+b \log _{2}\left(A / W_{t}\right)+c \log _{2}\left(A / W_{p}\right)
$$

여기서 $\mathrm{MT}$ 는 동작을 완수하는 데 필요한 평균시간, $\mathrm{a}, \mathrm{b}$ 와 $\mathrm{c}$ 는 상수로써 작업의 특성이나 작업 숙련도에 따라 결정 된다. $\mathrm{A}$ 는 대상 물체의 중심으로부터 측정한 거리이며, $\mathrm{W}_{\mathrm{t}}$ 는 이동방향으로 목적물의 폭이고, $\mathrm{W}_{\mathrm{p}}$ 이동경로의 폭이다.

Fitts + Steering 이동작업은 Figure 3과 같이 커서가 이동하는 동안 속도변화가 예상된다. B점과 C점 사이의 속 도는 궤도의 너비 때문에 시각적 피드백을 필요로 하는 구
간이고, C점 이후의 감속은 표적의 너비 때문에 시각적 피드 백이 필요한 구간이다.

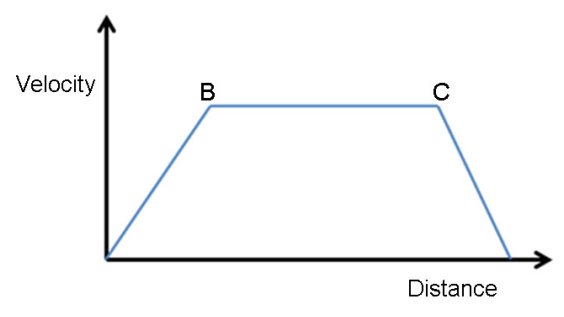

Figure 3. Movement distance and velocity in the Fitts + steering movement

본 연구에서는 Figure 1의 A점이 어떤 요인으로 인해 어 떤 위치에 설정되며, Figure 3의 B와 C점은 어떤 요인으로 인해 어떤 위치에 설정되는지를 조사할 것이다.

\section{Method}

실험에 참여한 피실험자들은 대학생 15 명 (남자 7 명, 여자 8명)이었다. 피실험자들의 평균 연령은 22.05세였다. 피실 험자들은 2가지 유형의 커서이동 작업을 수행하였다; (1) 경로 제약 없이 커서이동 + 도착지점의 위치 제한 있음, (2) 경로 제약하에서 커서이동 + 도착지점의 위치 제한 있음. 이 작업들을 수행하기 위한 실험 인터페이스는 비주얼 베이 직(6.0 버전)으로 제작하였다. 각 작업들의 난이도를 변화시 키면서 여러 가지 실험조건을 설정하였다.

Figure 4는 실험에서 사용된 발 마우스를 보이고 있다. 사 용된 발 마우스는 오른발을 움직임으로써 커서를 이동시킬 수 있었다. 즉 일반적인 손 마우스와 같은 기능을 갖고 있었 다. 왼쪽의 키패드 가장 오른쪽 상하로 위치한 붉은 색 버튼

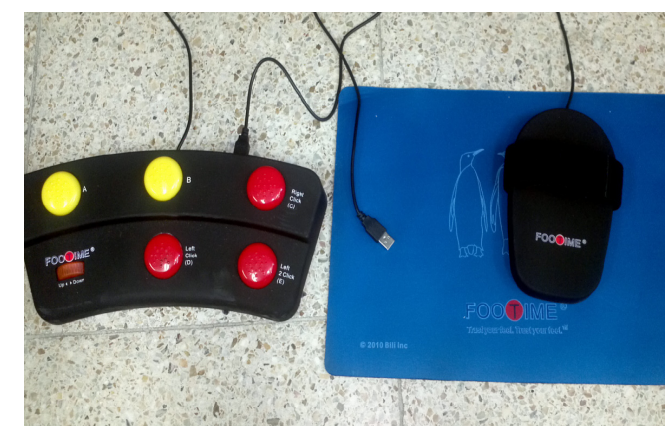

Figure 4. A foot mouse used in this experiment 
은 클릭을 위한 버튼과 버블 버튼이며 왼발을 사용하도록 되 어 있다. 다른 버튼들은 특수한 기능을 설정하도록 되어 있 다. 본 실험에서는 버튼들 중에서 클릭 버튼만을 사용했다. 발 마우스를 조작하기 위하여 피실험자들은 신발을 벗고, 슬 리퍼와 비슷하게 생긴 마우스에 오른발을 끼웠으며, 오른발 을 마우스 패드위에서 상하좌우로 이동함으로써 커서를 이 동시킬 수 있었다. 그리고 왼쪽의 키패드 가장 오른쪽 아래 의 붉은 색 버튼을 누름으로써 클릭의 기능을 수행하였다.

Figure 5는 커서를 직선으로 이동시켜서 정해진 목표물에 커서를 위치시키는 전형적인 Fitts' Law 실험이다. 커서의 이동경로는 특별한 제약이 없다. 피실험자가 가장 빠르게 움 직일 수 있는 경로를 스스로 선택하면 된다. 목표물의 너비 와 이동거리를 조정하여 실험조건을 변화시켰다. Figure 6은 제한된 직선경로를 통해 커서를 이동시키는 작업이고 Figure 7은 제한된 직선경로를 이동한 후에 목표물에 커서를 위치 시키는 작업을 위한 실험 인터페이스다. 이 작업의 실험조건 의 변화를 위해 너비, 높이 거리를 조절하였다.

한편 발 마우스는 평소 자주 사용하지 않던 근육을 사용 하기 때문에 충분한 훈련을 받지 못한 피실험자들은 발 마 우스를 사용할 때 수행도가 떨어질 것이다. 따라서 실험 전 에 발 마우스에 대한 충분한 학습을 실시하고 본 실험에 참

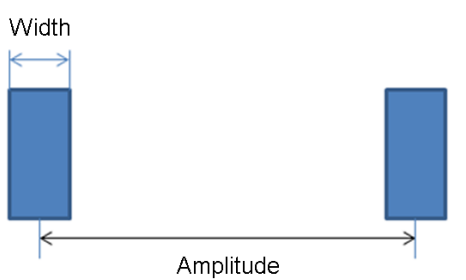

Figure 5. Interface for Fitts' movement experiment

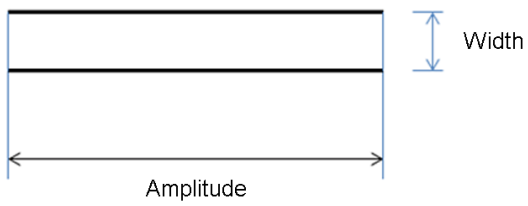

Figure 6. Interface for Steering movement experiment

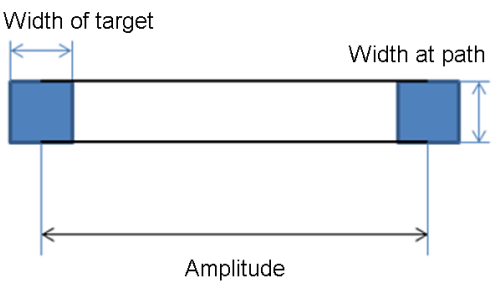

Figure 7. Interface for Fitts + Steering movement experiment
여하였다.

본 실험의 실험조건은 Table 1 과 같다. 각 조건에서 각 피실험자들은 10 회를 실시하였다. 피실험자들이 실험을 하 는 동안 고속 카메라를 사용하여 모니터 상의 커서이동화면 을 촬영하였고, 이 화면을 분석하여 커서이동속도의 변화와 각 작업을 수행하는데 소요된 시간을 측정하였다.

Table 1. Conditions for main experiments

\begin{tabular}{c|c|c|c}
\hline & $\begin{array}{c}\text { Fitts' } \\
\text { movement }\end{array}$ & $\begin{array}{c}\text { Steering } \\
\text { movement }\end{array}$ & $\begin{array}{c}\text { Fitts + Steering } \\
\text { movement }\end{array}$ \\
\hline Moving & 1,500 & 1,500 & 1,500 \\
distance & 2,500 & 2,500 & 2,500 \\
& 3,500 & 3,500 & 3,500 \\
\hline Width of & & 100 & 100 \\
path & & 300 & 300 \\
\hline Width of & 300 & 500 & 500 \\
Target & 500 & & 300 \\
\hline
\end{tabular}

*단위는 pixel이고 1,000 pixel은 $185 \mathrm{~mm}$ 길이임

\section{Results}

본 실험에 앞서 피실험자들을 대상으로 발 마우스 훈련을 Fitts 운동을 대상으로 실시하였다. 매일 30 분간 훈련을 실 시하였으며, 발 마우스 작업에 익숙해졌음을 확인하고 훈련 을 멈추었다. 충분히 훈련이 되었는지를 평가하기 위하여 훈 련과정에서 측정된 제어시간 데이터를 Figure 8과 같이 회 귀분석을 실시하였으며, 회귀모형상에서 첫 번째 실험 후의 측정시간과 두 번째 실험 후의 측정시간 사이의 시간을 초기 학습효과라 가정하고, 연속되는 훈련세션에서 (2)와 같이 초

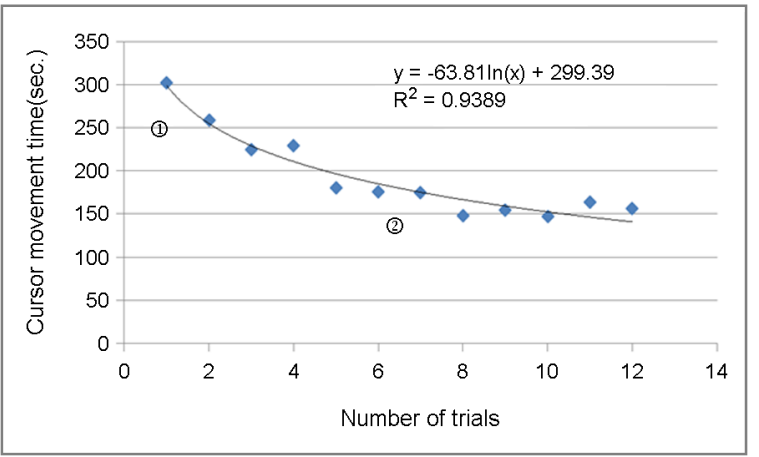

Figure 8. An example of velocity in Fitts' movement 
기 학습효과의 $20 \%$ 이하로 학습효과가 나타나면 충분히 학 습이 되었다고 가정하였다. 이러한 가정하에 모든 피실험자 들은 12회 미만의 훈련으로 충분히 학습이 되었다.

본 실험에서 마우스의 Fitts 운동을 위한 손 마우스와 발 마우스의 제어시간은 식(5), 식(6)와 같이 나타났다. 발 마 우스의 제어시간과 손 마우스의 제어시간모델의 기울기에 차이가 크게 나타났다. 즉 손 마우스의 정보처리 속도는 8.3 $\mathrm{bit} / \mathrm{sec}$ 이고 발 마우스의 정보처리 속도는 2.94 였다.

$$
\begin{array}{ll}
\text { 손 마우스: } M T=0.37+0.12 I D & \left(\mathrm{R}^{2}=0.82\right) \\
\text { 발 마우스: } M T=0.69+0.34 I D & \left(\mathrm{R}^{2}=0.92\right)
\end{array}
$$

Figure 1 상의 A점을 이후에는 커서로 목표물을 선택하 기 위해 커서의 위치와 목표물의 위치에 대한 지속적인 시 각적 피드백이 필요한 단계다. 발 마우스와 손 마우스의 경 우에 이 $\mathrm{A}$ 점이 어디에 형성되는지를 분석하였다. $\mathrm{A}$ 점의 형 성지점이 발 마우스와 손 마우스 사이에 차이를 보이지 않 았다. 손 마우스와 발 마우스를 사용하여 제어작업을 수행한 경우, 거리 축 상의 전체이동 거리를 1 이라 할 때 $0.3 \sim 0.7$ 사이에 있으며, 시간 축 상의 이동시간을 1 로 보았을 때는 0.3 0.6 사이에 A지점이 형성되었다. A지점 형성시간에 대 한 T-test의 결과는 유의수준 $95 \%$ 에서 $p$ 값이 0.93 이었 고, A지점 형성위치에 대한 $\mathrm{T}$-Test의 결과는 유의수준 $95 \%$ 에서 $p$ 값이 0.21 이였다.

직선 궤도 내로 커서를 이동시키는 Steering 작업에서 손 마우스와 발 마우스의 수행도는 다음과 같이 나타났다. Steering 작업에서는 선형식의 기울기에 차이가 거의 없었 다. 이는 작업 난이도가 증가하더라도 발 마우스의 수행도는 떨어지지 않는다는 것을 뜻한다.

$$
\begin{aligned}
& \text { 손 마우스: } M T=1.12+0.09 I D \quad\left(\mathrm{R}^{2}=0.48\right) \\
& \text { 발 마우스: } M T=2.49+0.11 I D \quad\left(\mathrm{R}^{2}=0.45\right)
\end{aligned}
$$

Fitts + Steering 작업에서 손 마우스와 발 마우스의 제어 시간과 작업 난이도의 관계는 식(9)과 식(10)과 같다. 여기 서 $\mathrm{ID}_{\mathrm{t}}=\log _{2}\left(\mathrm{~A} / \mathrm{W}_{\mathrm{t}}\right)$ 이고, $\mathrm{ID}_{\mathrm{p}}=\log _{2}\left(\mathrm{~A} / \mathrm{W}_{\mathrm{p}}\right)$ 이다.

$$
\begin{aligned}
& \text { 손 마우스 : } \\
& M T=0.56+0.27 I D_{t}-0.05 I D_{p} \quad\left(\mathrm{R}^{2}=0.54\right)
\end{aligned}
$$

발 마우스 :

$$
M T=1.40+0.51 I D_{t}-0.04 I D_{p} \quad\left(\mathrm{R}^{2}=0.73\right)
$$

Figure 3 의 B지점과 C지점이 어디에 형성되는지를 조사
하였다. B지점에서 $\mathrm{C}$ 지점 사이는 커서를 제한된 궤도 내에 유지하기 위해 커서의 위치와 궤도의 위치에 대한 시각적 피 드백이 필요한 구간이며, C지점 이후는 목표물을 선택하기 위해 커서의 위치와 목표물의 위치에 대한 지속적인 시각적 피드백이 필요한 구간이다.

$\mathrm{B}$ 지점의 위치 측정 결과는 Figure 9 와 같다. $\mathrm{B}$ 지점 형성 위치가 손 마우스와 발 마우스가 다른지를 알아보기 위해 실 시된 T-test의 결과는 유의수준 $95 \%$ 에서 $p$ 값 $=0.006$ 으로 시간 축 상에서 $\mathrm{B}$ 지점 형성에 차이가 있었으며, 거리 축 상에서도 $p$ 값 $=0.0001$ 으로 차이가 존재하였다.

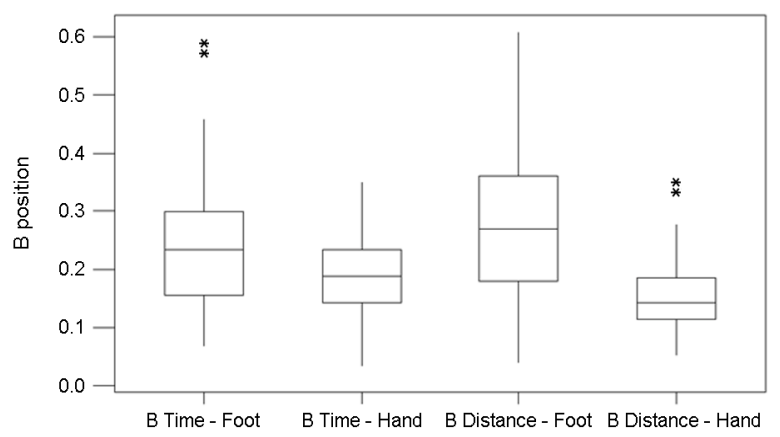

Figure 9. B position in the Fitts + Steering movement

발 마우스와 손 마우스에 의한 커서이동 작업에서 시간 축과 거리 축 상에 C지점의 형성위치는 Figure 10 과 같다. C지점의 형성 시간과 형성 위치도 각각 유의수준 $95 \%$ 에 서 $p$ 값 $=0.0001$ 과 $p$ 값 $=0.045$ 로 발 / 손 마우스 간에 차이가 존재하는 것으로 분석되었다.

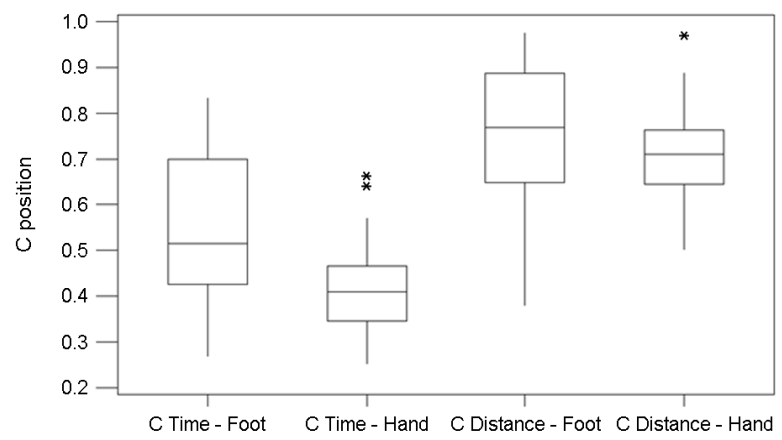

Figure 10. C position in the Fitts + Steering movement

마우스 작업을 수행할 때 생기는 정신적인 작업부하를 측 정하기 위해 NASA-TLX를 사용하였다. NASA-TLX 값 에 대한 ANOVA 분석결과, 손 마우스보다 발 마우스가 통 
계적으로 유의하게 정신적 작업부하를 느끼게 했다 $[F(1$, 84) $=64.71, p<0.001]$. 한편, 작업의 종류에 따라 상이한 정신적 작업부하를 유발했다 $[F(2,84)=3.59, p<0.05]$. 작업이 복잡할수록 $($ Fitts + Steering 작업) 피실험자들은 더 많은 작업부하를 느꼈다. 그러나 마우스의 종류와 마우스 작업 종류 사이에 교호작용은 없었다 $[F(1,56)=3.9, p=$ 0.84].

\section{Conclusion}

손 마우스의 조작시간이 Fitts' 법칙, Steering 법칙 그리 고 Fitts' + Steering 법칙을 따르듯이 발 마우스도 이러한 법칙들을 따르고 있음을 확인할 수 있었다. 한편, 손 마우스 의 조작에서와 같이 본 연구는 발 마우스를 사용할 때, 세 가지 작업에서 인간의 수행도와 시각적 피드백의 효과를 손 마우스를 사용하는 경우와 비교하여 분석하였다. Fitts 운동, Steering 운동 그리고 Fitts와 Steering 운동의 혼합형 운 동에서 발 마우스의 조작시간이 더 많이 소요되었다. 이러한 현상은 인간이 손을 사용하는 경우보다 발을 사용하는 경우, 수행도가 떨어지기 때문일 것이다. 그러나 발 마우스에 의한 Steering 운동에서는 작업의 난이도가 증가하더라고 현저하 게 조작시간이 증가하지 않았다. 이는 발 마우스를 사용할 때 목표물을 선택하는 작업보다는 Steering 이동작업과 같 이 커서 이동작업에 효율적임을 알 수 있었다. 동일한 결과 가 정신적인 작업부하 측정값에서도 나타났다. 다른 작업보 다 Steering 작업에서 정신적 작업부하가 적게 나타났다.

발 마우스를 사용할 때, 시각적 피드백이 필요한 시점에 대한 분석결과는 작업의 유형에 따라 달리 나타났다. Fitts 운동의 경우는 손 마우스와 발 마우스 사이에 차이가 없었다. 그러나 발 마우스를 사용한 Fitts와 Steering 운동의 혼합 형 운동에서 피실험자들은 목표물에 더 가까이 점근했을 때 시각적 피드백을 이용하고 있었다. 이는 발 마우스를 조작할 때에 소요되는 시간이 길기 때문에 나타나는 현상으로 보 인다.

본 연구에서 손 마우스와 발 마우스를 비교함으로써 발 마 우스의 한계점을 알 수 있었다. 그러나 발 마우스는 손 마우 스를 사용할 수 없는 장애인에게는 긴요한 입력장치이기 때 문에 장애인을 대상으로 한 연구가 지속적으로 수행되고, 이 를 통해 발 마우스를 개선해야 할 것입니다. 또한 발 마우스 의 사용성이 개선된다면, 일반인들도 보조입력장치로 사용할 수도 있을 것이다. 예를 들어, 본 연구의 결과처럼, 단순 이 동작업은 발 마우스를 사용하고 선택작업은 손 마우스를 사 용할 수 있을 것이다. 추후연구로는 여러 종류의 발 마우스
들을 비교 분석하여, 어떤 특성을 갖는 발 마우스가 어떤 작 업에 더 효율적인지에 대한 연구를 수행할 예정이다.

\section{Acknowledgements}

The research was supported by a grant from the Academic Research Program of Korea National University of Transportation in 2012 .

\section{References}

Accot, J. and Zhai, S., "Beyond Fitts' Law: Models for Trajectory-based HCI Tasks," CHI conference 1997, 295-302, 1997.

Dennerlein, J. T., Martin, D. B. \& Hasser, C., "Force-feedback Improves Performance for Steering and Combined Steering-targeting Tasks," CHI conference 2000, 423-429, 2000.

Drury, C. G., Movements with Lateral Constraint, Ergonomics, 14(2), 293 $-305,1971$.

Fitts, P. M., The information capacity of the human motor system in controlling the amplitude of movement, Journal of Experimental Psychology, 47, 381-391, 1954.

Garcia, F. P. \& Vu, K-P. L., Effectiveness of hand- and foot-operated secondary input devices for word-processing tasks before and after training, Computer in Human Behavior, 27, 285-295, 2011.

Godthelp, H., The limits of path error-neglecting in straight lane driving, Ergonomics, 31(4), 609-619, 1988.

Hong, S-K. \& Kim S-I., Time prediction model of cursor movement with path constraints, Journal of the Korean Institute of Industrial Engineers, 31(4), 334-340, 2005

Hong, S-K. \& Park, J-C., "Ballistic movement range in the foot mouse control", Spring Conference of the Ergonomics Society of Korea, 219-222, 2008

Kang, J-Y, Kim, Y-A, Lee, N-Y, Lee, S-H. \& Hwang, M-C., "Development of foot mouse for the disabled", Fall Conference of the Ergonomics Society of Korea, 614-617, 2008.

Lee, K-T, Jang, P-S. \& Lee, D-H., Optimal display-control gain of the foot-controlled isotonic mouse on a target acquisition task, IE Interface, 17(1), 112-120, 2004.

Mackenzie, I. S., Fitts' Law as a research and design tool in human computer interaction, Human-Computer Interaction, 7, 91-139, 1992.

Mackenzie, I. S., Zhang, S. X. \& Soukoreff, R. W, Text entry soft keyboards, Behavior \& Information Technology, 18(4) 235-244,1999.

Springer, J. \& Siebes, C., "Position controlled input device for handicapped: Experimental studies with a footmouse", International Journal of Industrial Ergonomics, 17, 135-152, 1996.

Winsum, W. V., Speed choice and steering behavior in curve driving, Human Factors, 38(3), 434-441, 1996. 


\section{Author listings}

\section{Seung-Kweon Hong: skhong@ut.ac.kr}

Highest degree: Ph.D., Department of Industrial Engineering, State University of New York at Buffalo

Position title: Associate Professor, Department of Industrial \&

Management Engineering, Korea National University of Transportation

Areas of interest: HCI, System Safety, Cognitive Engineering

\section{Seon-Soo Kim: zeigeist@ut.ac.kr}

Highest degree: MS, Department of Industrial \&Management Engineering, Korea National University of Transportation

Position title: Researcher, Korea Atomic Energy Research Institute

Areas of interest: Cognitive Engineering, HCI, Usability Engineering

Date Received : 2012-09-07

Date Revised :2012-11-28

Date Accepted : 2012-11-28 